\title{
Three-dimensional CT scan for Swyer-James syndrome
}

\author{
Satoshi HAGIMOTO ${ }^{1}$ \\ Gen OHARA ${ }^{1}$ \\ Kunihiko MIYAZAKI ${ }^{1}$ \\ Hiroaki SATOH ${ }^{1}$
}

\author{
${ }^{1}$ Division of Respiratory Medicine, Mito Medical Center, Tsukuba University, \\ Mito, Japan \\ ${ }^{1}$ Tsukuba Üniversitesi Mito Tıp Merkezi, Solunum Bölümü, Mito, Japonya
}

To the Editor,

A 16-year-old woman was referred due to a left hyperlucent lung, which was incidentally observed on a chest radiograph (Figure 1A). The patient had a history of respiratory infection in her infancy. A threedimensional (3-D) CT scan revealed hyperlucency and diminished vascularity in the left lung without any bullous lunglesions (Figure1B). On the basis of these findings, the patient was diagnosed to have Swyer-James syndrome $(1,2)$. When unilateral hyperlucent lung is discovered, a 3-D CT scan would provideimportant clinical information as observed in this case. Although extremely rare, Swyer-James syndrome should be included in the differential diagnosis of unilateral hyperlucent lungif patients have a history of pulmonary infection in their early childhood.
3-D CT scan would provide critical information in distinguishing between "Swyer-James syndrome" and "other diseases exhibiting unilateral hyperlucent lung". In addition, information obtained by 3-D CT scan would advance differential diagnosis without any other invasive examination, therefore, there would be benefits of low invasiveness and economic merit for patients.

\section{Yazışma Adresi (Address for Correspondence)}

Dr. Hiroaki SATOH

Division of Respiratory Medicine, Mito Medical Center, Tsukuba University, MITO - JAPAN

e-mail: hirosato@md.tsukuba.ac.jp 


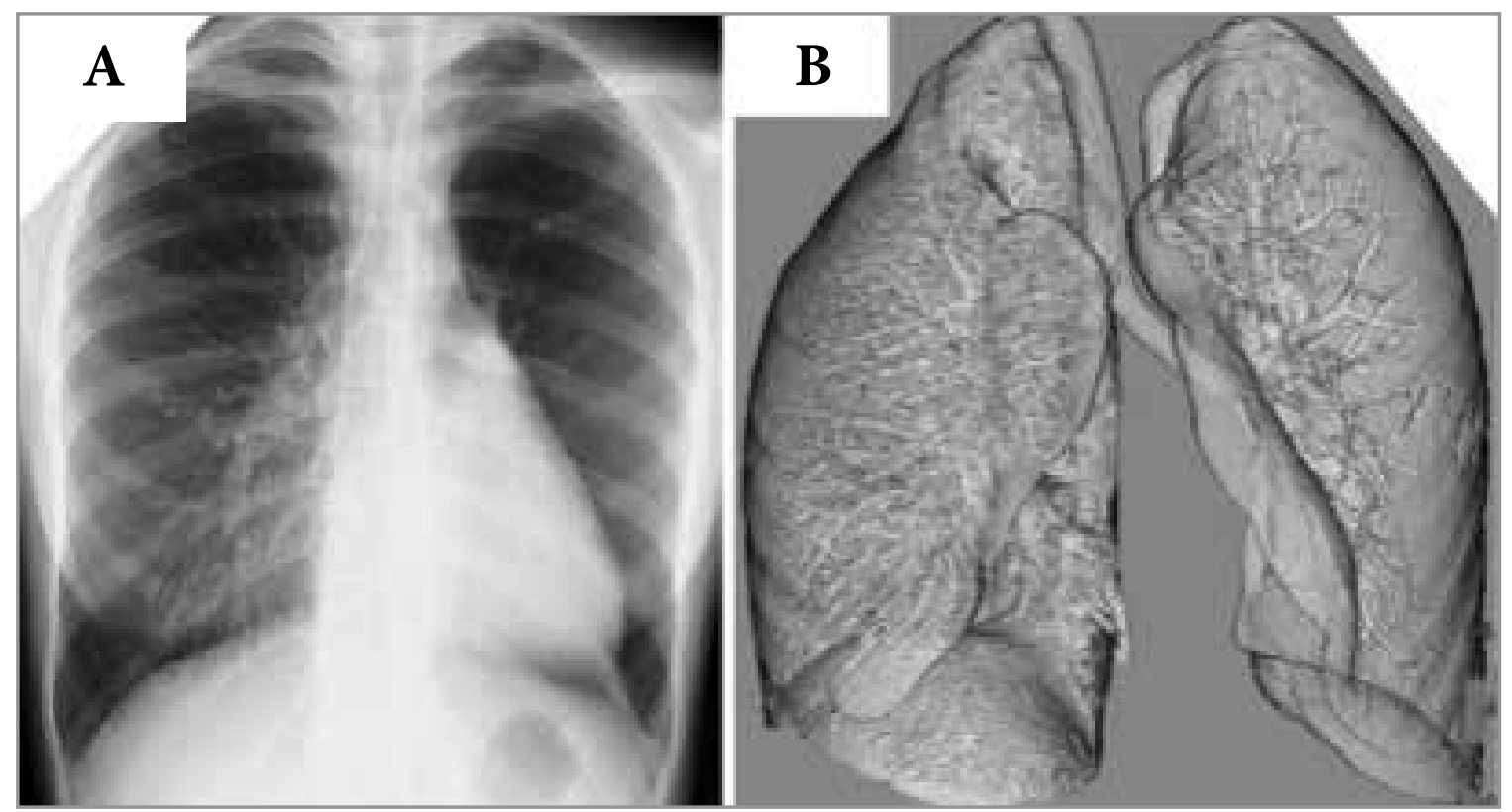

Figure 1. (A) Plain chest radiograph. (B) Three-dimensional (3-D) CT scan revealed hyperlucency and diminished vascularity in the left lung without any bullous lung lesions.

\section{REFERENCES}

1. Swyer PR, James GCW. A case of unilateral pulmonary emphysema.Thorax 1953;8:133-6.

2. Marti-Bonmati L, Ruiz Perales F, Catala F, Mata JM, Calonge ECT findings in Swyer-James syndrome. Radiology 1989; 172:477-80. 